\title{
The prevalence of radiographic vertebral fractures in Mexican men
}

\author{
P. Clark • F. Cons-Molina • M. Deleze • J. O. Talavera • \\ L. Palermo $\cdot$ S. O. Cummings
}

Received: 22 July 2009 /Accepted: 21 September 2009 /Published online: 21 November 2009

(C) The Author(s) 2009. This article is published with open access at Springerlink.com

\begin{abstract}
Summary The prevalence of radiographically ascertained vertebral fractures in a random sample of 413 in Mexican men is $9.7 \%$ (95\% CI $6.85-12.55)$. Increase of vertebral fracture rises with age from $2.0 \%$ in the youngest group (5059 years) to $21.4 \%$ in the oldest group ( 80 years and over). Introduction This is the first population-based study of vertebral fractures in Mexican men using a standardized methodology reported in other studies.
\end{abstract}

\footnotetext{
P. Clark $(\bowtie)$

Clinical Epidemiology Unit, Hospital Infantil de Mexico Federico

Gómez-Faculty of Medicine UNAM,

Blvd. Virreyes 1010, Lomas de Chapultepec,

Mexico City 11000 DF, Mexico

e-mail: patriciaclark@prodigy.net.mx

F. Cons-Molina

Arthritis and Osteoporosis Research Center,

Mexicali, BC, Mexico

M. Deleze

Hospital Los Angeles,

Puebla, Mexico

J. O. Talavera

Coordinación de Investigación en Salud CMN Siglo XXI-IMSS,

Centro de Investigación en Ciencias Médicas, UAEMéx,

Mexico City, Mexico

L. Palermo

Department Epidemiology and Biostatistics,

University of California,

San Francisco, USA

\section{S. O. Cummings}

San Francisco Coordinating Center, California Pacific Medical Center Research Institute and University of California,

San Francisco, USA
}

Methods The presence of radiographic vertebral fractures increases with age. This same pattern was found in Mexican women with steady age increments, but the higher prevalence of fractures in women starts at age 70 , whereas in men, the higher prevalence starts a decade later ( 80 years and over).

Results The standardized prevalence per 1,000 men 50 years and over in the Mexican population for the year 2005 is 65.8 (95\% CI $29.9-105.5$ ), and it is 68.6 (95\% CI $32.2-108.7)$ in the US population for the year 2000.

Keywords Epidemiology · Mexican men · Prevalence · Vertebral fractures

\section{Introduction}

In the last decade, osteoporosis and fragility fractures in men received more attention than previously because of new awareness of those conditions on the health system. They account for one-third of all fractures in individuals 50 years and over and for one-fourth of the total costs associated with fractures [1]. It has also been documented that fragility fractures in men lead to higher morbidity and mortality than women [2,3]. Vertebral fractures in men have been associated with reduced function, increased dependency, and poor quality of life. Men with symptomatic vertebral fractures commonly complain of back pain, loss of height, and kyphosis; they also have significantly less energy, poor sleep patterns, more emotional problems, and impaired mobility when compared with age-matched control subjects. About $20 \%$ of asymptomatic vertebral fractures that get clinical attention occur in men [4].

It has been suggested that race and geography might play a role in the different figures of fragility fractures in 
men. Whites have a higher rate than African-Americans, and Asians have a lower likelihood of having hip fractures.

In Mexico, one out of 20 Mexican men and one out of 12 Mexican women older than 50 years of age will sustain a hip fracture [5]. The rate of radiographically defined vertebral fractures in Mexican women is high [6] (overall rate of $19.2 \%$ ), but no data regarding the epidemiology of vertebral fractures in men have been published. The aim of the present study was to determine the prevalence of radiographically defined vertebral fractures by age in a random sample of Mexican men over 50 years and to identify potential conventional risk factors associated with vertebral fractures in this group.

\section{Methods}

\section{Study design}

A radiographical survey was designed for this study; 413 Mexican men were included from a population-based random sample in the city of Puebla. The random probability sample was generated with the advice of the National Institute of Geography and Statistics (INEGI) in Mexico. We used the last census available to build a stratified sample of 100 men for the following age groupings: $50-59,60-69,70-79$, and $\geq 80$. We used the demographic information available from every district and group of households blocks within the city and we used the maps and cartography provided by INEGI during the survey.

Before the study began, a training workshop was held with the interviewers to review the questionnaire and survey methods.

Eligible men participated in a face-to-face interview in their homes; after the interview, they were asked to have lateral X-rays of the thoracic and lumbar spine taken. If a man was unable or unwilling to participate, he was replaced by the first man available of the same age stratum, making home visits to houses from right to left of the first assigned house in the same block of households until a man who fulfilled the criteria was found.

The protocol was submitted to and approved by the Institutional Review Board, and a written consent of all participants was obtained before the interview.

\section{Questionnaire}

The questionnaire used was originally designed for Latin American Vertebral Osteoporosis Study (LAVOS) [6]. All questions were developed based on the questionnaires of two large studies, the European Prospective Osteoporosis Study (EPOS) and the Study of Osteoporotic Fractures
(SOF) [7, 8], and collected self-reported data on demographics, lifestyle factors, and conventional risk factors for osteoporosis [9]. To assess dietary calcium, we included a semi-quantitative food questionnaire validated in Spanish for the Mexican population [10]. The Sistema de Nutrimientos (SNUT) program was used to compute dietary calcium in milligram per day. Commercial calcium supplement intake was calculated according to names and daily doses reported by participants. Alcohol intake was calculated in grams per day (gr/day) using the SNUT program and categorized accordingly to the World Health Organization Audit Program [11] as: never for the subject who did not report alcohol intake, mild from 1-10 gr/day, moderate from 11-40 gr/day, and severe for more than $40 \mathrm{gr} /$ day. The questions assessed the frequency and type of alcoholic beverage during the last year. Physical activity was assessed in minutes per day in accordance to time spent in various activities, including walking, dancing, and cycling among others, and computed for 1 week in the previous year during these activities. Height $(\mathrm{cm})$ was determined by a stadiometer to the nearest $0.1 \mathrm{~cm}$; weight $(\mathrm{kg})$ was assessed using a regularly calibrated scale to the nearest $0.1 \mathrm{~kg}$; and the body mass index (BMI) was computed as weight $(\mathrm{kg})$ divided by the square of the height $\left(\mathrm{m}^{2}\right)$, usually defined as a BMI of 19-24.9, overweight 25-29.9, and obese $>30$. All other risk factors were self-reported. The questionnaire was originally used for the LAVOS study, terms were for clarification, and the instrument was standardized. We found a $16.5 \%$ nonrespondent rate during the survey.

\section{Radiology}

Lateral thoracic and lumbar spine radiographs were taken with a 40" tube-to-film distance according to a standard protocol that included details concerning positioning of subjects and radiographic technique. Radiographs were taken with the subject in the left lateral position. The breathing technique was used for the thoracic films. The thoracic film was centered at $\mathrm{T} 7$ and the lumbar film at L2. All radiographic studies were done in the same department and collected in our morphometry center in Mexicali. A sample of radiographs was sent to the same center early in the study to verify quality assessment and compliance with the protocol.

All study radiographs were digitized using an AccuTab ${ }^{\circledR}$ table, and vertebral dimensions were measured by placement of six points defining the margins of each vertebral body using a cursor with a peripheral device that enters the value of vertebral height in software specially designed to create a database. Six points were marked on each vertebral body from $\mathrm{T} 4$ to $\mathrm{L} 4$ to define vertebral shape and to describe three vertebral heights - $\mathrm{Ha}$ (anterior), $\mathrm{Hm}$ (medial), and Hp (posterior) - using the same criteria as SOF $[12,13]$. 
The central reader was trained at the San Francisco Coordinating Center to ensure that the positioning of points was similar to that used in the Study of Osteoporotic Fractures and the Beijing Osteoporosis Project [14]. To test the comparability of the method, a random sample of $10 \%$ of Mexican radiographies were sent to San Francisco for morphometric measurements. A good degree of agreement (kappa $=0.77,95 \%$ CI $0.64-0.90$ ) was found between readers at the San Francisco Coordinating Center at San Francisco and the Mexican Morphometry Center regarding the identification of normal and abnormal vertebras.

\section{Definition of vertebral deformity}

We used the modified Eastell criteria to define vertebral fracture, and we used the same criteria used in SOF to place the six points in each vertebra $[15,16]$. This method starts by deriving normal values of vertebral dimensions from the study population using the statistical trimming method described by Black [12]. The reference normal values for the Latin American countries participating in this study were derived by a biostatistician (L.P.) at the San Francisco Coordinating Center.

A fracture was diagnosed in a vertebral body based on measurements of vertebral heights. A fracture was defined if there was a reduction of three SDs or more from the normal mean for the vertebral level of anterior-to-posterior or middle-to-posterior heights ratios. In addition, a vertebral body was defined as fracture if both the ratio of posteriorto-adjacent posterior and the anterior heights-to-adjacent anterior were reduced by three SDs or more from normal values.

\section{Analysis}

The prevalence of asymptomatic vertebral fractures was calculated for each age stratum with a 95\% confidence interval. A man with at least one vertebral deformity was considered a case of vertebral fracture. The prevalence of the different risk factors was also estimated in this group. We use a bivariate analysis to estimate the odds ratio and $95 \%$ confidence interval; this was followed by a multivariate method - Cox regression model as suggested by Barros AJ and Hirakata [17] to adjust for the different risk factors and the prevalence ratio with $95 \%$ confidence interval was estimated. Additionally, we estimated the odds ratios using a logistic regression model (full model and stepwise) as both methods are widely used to report this type of findings. Finally, the prevalence of vertebral fractures was age-standardized with the direct method against Mexican and US populations for comparison [18, 19]. Statistical analyses were performed using Statistical Package for the Social Sciences (12th edition).
Table 1 Prevalence of vertebral fractures per age strata

\begin{tabular}{lcc}
\hline Age & Total $N($ num. of fx) & PV 95\% IC \\
\hline $50-59$ & $101(2)$ & $1.9(0-4.7)$ \\
$60-69$ & $103(8)$ & $7.6(2.4-12.8)$ \\
$70-79$ & $106(8)$ & $7.6(2.5-12.6)$ \\
$80>$ & $103(22)$ & $21.4(13.3-29.4)$ \\
\hline
\end{tabular}

\section{Results}

The present analysis is based on a total sample of 413 men who had morphometric measurements of their spine radiographs. Table 1 shows the prevalence of vertebral fractures by age strata. As expected, the prevalence of vertebral fracture steadily increased from ages 50-59 years to over 80 years, with a prevalence of $2 \%(95 \%$ CI $-0.74-4.70)$ among those $50-59$ years to $21.4 \%(13.45-29.27)$ in those 80 years and over $(p=0.0001)$.

The prevalence of potential risk factors for fracture is shown in Table 2. It is important to note the high

Table 2 Characteristics of participants

\begin{tabular}{lc}
\hline Variable & Mexican men $n=413$ \\
\hline Age (mean $\pm \mathrm{sd})$ & $68.99 \pm 11.64$ \\
Height $($ mean $\pm \mathrm{sd})$ & $159.77 \pm 6.69$ \\
Weight $($ mean $\pm \mathrm{sd})$ & $69.39 \pm 12.05$ \\
Maternal history of Fx & $2.4 \%$ \\
Personal history of Fx & $13.3 \%$ \\
Body mass index & \\
Underweight & $1.2 \%$ \\
Normal & $27.4 \%$ \\
Overweight & $49.4 \%$ \\
Obese & $22.0 \%$ \\
Height loss & $42.4 \%$ \\
Calcium $\geq 800$ mg & $17.9 \%$ \\
Use of steroids & $1.0 \%$ \\
Smoking & \\
Current smoking & $22.8 \%$ \\
Ever smokers & $40.4 \%$ \\
Never smokers & $36.8 \%$ \\
Alcohol intake & \\
Never & $46.0 \%$ \\
$1-10$ gr/day & $48.9 \%$ \\
Physical activity & $0.5 \%$ \\
$\geq 30$ min/day & $4.6 \%$ \\
\hline & \\
\hline & \\
\hline &
\end{tabular}


prevalence in some of these factors: a little over $40 \%$ of the sample had height loss and the proportion of men who were overweight and obese was very high (49.4 and $22.0 \%$, respectively); almost half the sample (48.2\%) met the minimal recommendations of physical activity ( $\geq 30 \mathrm{~min} /$ day). Less than one-fourth $(22.8 \%$ ) were active smokers, and only $17.9 \%$ of the sample included $\geq 800 \mathrm{mg}$ of calcium in their diets. The multivariate analysis shows a tendency for height loss, but there are no significant differences in any of the risk factors evaluated between the fracture and nonfracture groups (see Table 3). The standardized prevalence per 1,000 men 50 years and over in the Mexican population for the year 2005 are $65.8(95 \%$ CI 29.9-105.5), and they are 68.6 (95\% CI 32.2-108.7) in the US population for the year 2000 .

\section{Discussion}

This is the first study that reports the prevalence of vertebral fractures in Mexican men in which there was an overall prevalence of $9.7 \%$ (95\% CI $6.85-12.55)$. The prevalence of vertebral fractures in men is half the prevalence estimated for women $(19.2 \% 95 \%$ CI 15.3 33.0) recently published in the LAVOS study using the same methodology [6]. The presence of vertebral fractures rises with age from $2.0 \%$ in the youngest group (5059 years) to $21.4 \%$ in the oldest group ( 80 years and over). This same pattern were found in Mexican women with steady age increments, but the higher prevalence in women starts at age 70, whereas in men, the higher prevalence starts a decade later ( 80 and over). Different

Table 3 Risk factors for vertebral fracture in Mexican men

\begin{tabular}{|c|c|c|c|c|c|c|}
\hline Variable $^{\mathrm{a}}$ & $N 413^{\mathrm{b}}$ & $\%$ & Bivariate OR (IC 95\%) & $p$ value & Multivariate OR (IC 95\%) & $p$ value \\
\hline \multicolumn{7}{|c|}{ Maternal history of fractures } \\
\hline No & $39 / 403$ & 9.7 & 1 & & 1 & \\
\hline Yes & $1 / 10$ & 10.0 & $1.04(0.02-7.84)$ & 0.97 & $1.37(0.15-12.64)$ & 0.77 \\
\hline \multicolumn{7}{|c|}{ History of fracture } \\
\hline No & $32 / 358$ & 8.9 & 1 & & 1 & \\
\hline Yes & $8 / 55$ & 14.5 & $1.73(0.69-4.23)$ & 0.28 & $1.57(0.612-4.03)$ & 0.34 \\
\hline \multicolumn{7}{|l|}{ Body mass index } \\
\hline Underweight & $0 / 5$ & 0 & & & & \\
\hline Normal & $12 / 113$ & 10.6 & 1 & & 1 & \\
\hline Overweight & $19 / 204$ & 9.3 & $0.86(0.38-1.98)$ & 0.85 & $1.09(0.47-2.50)$ & 0.82 \\
\hline Obese & 9/91 & 9.9 & $0.92(0.34-2.50)$ & 0.95 & $1.65(0.59-4.58)$ & 0.33 \\
\hline \multicolumn{7}{|l|}{ Height loss } \\
\hline No & $11 / 198$ & 5.6 & 1 & & 1 & \\
\hline Yes & $26 / 175$ & 14.9 & $2.97(1.35-6.63)$ & 0.068 & $2.08(0.94-4.61)$ & 0.06 \\
\hline \multicolumn{7}{|l|}{ Calcium dietary } \\
\hline$<800 \mathrm{mgs}$ & $34 / 339$ & 10.0 & 1 & & 1 & \\
\hline$\geq 800 \mathrm{mgs}$ & $6 / 74$ & 8.1 & $1.26(0.48-3.50)$ & 0.77 & $0.66(0.25-1.74)$ & 0.40 \\
\hline \multicolumn{7}{|l|}{ Smoking } \\
\hline Never & $12 / 152$ & 7.9 & 1 & & 1 & \\
\hline Ever & $19 / 167$ & 11.4 & $1.50(0.66-3.42)$ & 0.37 & $1.45(0.64-3.29)$ & 0.37 \\
\hline Current & $9 / 94$ & 9.6 & $1.24(0.46-3.13)$ & 0.37 & $1.56(0.58-4.21)$ & 0.37 \\
\hline \multicolumn{7}{|c|}{ Alcohol intake gr/d } \\
\hline Never & $23 / 190$ & 12.1 & 1 & & 1 & \\
\hline $1-10$ & $16 / 202$ & 7.9 & $0.67(0.30-1.28)$ & 0.44 & $0.74(0.35-1.58)$ & 0.40 \\
\hline $11-40$ & $0 / 2$ & 0 & & & & \\
\hline$>40$ & $1 / 19$ & 5.3 & $0.40(0.01-2.82)$ & 0.48 & $0.46(0.05-3.89)$ & 0.48 \\
\hline \multicolumn{7}{|l|}{ Physical activity } \\
\hline 0-29 $\mathrm{min} /$ day & $16 / 117$ & 13.7 & 1 & & 1 & \\
\hline$\geq 30 \mathrm{~min} /$ day & 13/199 & 6.5 & $0.49(0.21-1.20)$ & 0.19 & $0.56(0.24-1.32)$ & 0.19 \\
\hline
\end{tabular}

${ }^{\text {a }}$ Multivariable analysis adjusted by age

${ }^{\mathrm{b}}$ Number of positive observations/total observations for each factor 
patterns have been reported in different regions and countries. The European Vertebral Osteoporosis Study [7] found an overall similar frequency of vertebral deformities in their study in 19 European countries, but their sample did not include subjects older than 75 years of age, whereas the substantial increments of vertebral fractures are found in other studies. A higher incidence of vertebral fracture in men was reported in the Rotterdam study, and the incidence increased with age [20]. Similar results were found in the EPOS study where the rate of incidence of morphometric fracture was 9.9 in 1,000 women aged 50-79 per year, with a rate approximately one-half which is 5.7 in 1,000 men per year [21]. Differences in the prevalence between genders have also been reported in the United States (14\% in men and 19\% in women [22] In Asia, the prevalence in women 65 years and over was $20 \%(18-22 \%)$ and in men, $12.5 \%$ (1114\%) [23]. We conclude that vertebral fractures are more frequent in older age Mexican men, and these figures have to be taken into consideration by Mexican health authorities as they plan future programs oriented to prevent and treat fragility fractures in men.

Included in our questionnaire were several clinical risk factors known to be associated with osteoporosis and fractures, but we were not able to demonstrate differences between the fracture and nonfracture group. The fracture group had a higher frequency of self-reported height loss, however, only a tendency of this was shown in the bivariate and multivariate analysis.

This study has several strengths. The results were based on a random community sample and there was a high rate of participation. This study followed the standardized approaches for recruiting participants, obtaining X-rays, and assessing potential risk factors, and all of the films were assessed centrally using the same methods that have been employed in international studies and in the LAVOS study [6].

Our study also had limitations. It was not specifically designed to characterize the risk factors for vertebral fracture in men; therefore, the sample size was not large enough to find significant association with the risk. As it was a cross-sectional study, we could not assess the association of pain or symptoms with vertebral fractures.

In conclusion, vertebral fractures in Mexican men over 50 years are frequent, it increases with age, and the rise stops after the age of 70 years. Compared with Mexican women, the prevalence of men with vertebral fractures is half that reported for Mexican women using the same methodology (9.7 vs. 19.2, respectively). This pattern of presentation is similar to that reported for other countries.

These figures should alert clinicians and health authorities to this health problem in older Mexican men. Mexico should implement measures to identify vertebral fractures so as to allocate resources for the treatment and prevention of this condition because, with the growing number of the elderly and the future increments in life expectancy in this country, vertebral fractures could rise to epidemic proportions.

Acknowledgments This study was supported by a grant awarded by CONACYT Mexico (Sectorial-41097)

\section{Conflicts of interest None}

Open Access This article is distributed under the terms of the Creative Commons Attribution Noncommercial License which permits any noncommercial use, distribution, and reproduction in any medium, provided the original author(s) and source are credited.

\section{References}

1. Burge R, Dawson-Hughes B, Solomon DH, Wong JB, King A, Tosteson A (2007) Incidence and economic burden of osteoporosis-related fractures in the United States, 2005-2025. J Bone Miner Res 22:465-475

2. Cooper C, Atkinson EJ, Jacobsen SJ, O'Fallon WM, Melton LJ 3rd (1993) Population-based study of survival after osteoporotic fractures. Am J Epidemiol 137:1001-1005

3. Pande I, Scott DL, O'Neill TW, Pritchard C, Woolf AD, Davis MJ (2006) Quality of life, morbidity, and mortality after low trauma hip fracture in men. Ann Rheum Dis 65:87-92

4. Scane AC, Francis RM, Sutcliffe AM, Francis MJ, Rawlings DJ, Chapple CL (1999) Case-control study of the pathogenesis and sequelae of symptomatic vertebral fractures in men. Osteoporos Int 9:91-97

5. Clark P, Lavielle P, Franco-Marina F, Ramirez E, Salmeron J, Kanis JA, Cummings SR (2005) Incidence rates and life-time risk of hip fractures in Mexicans over 50 years of age: a populationbased study. Osteoporos Int 16:2025-2030

6. Clark P, Cons-Molina F, Deleze M, Ragi S, Haddock L, Zanchetta JR, Jaller JJ, Palermo L, Talavera JO, Messina DO, Morales-Torres J, Salmeron J, Navarrete A, Suarez E, Perez CM, Cummings SR (2009) The prevalence of radiographic vertebral fractures in Latin American countries: the Latin American Vertebral Osteoporosis Study (LAVOS). Osteoporos Int $20: 275-282$

7. O’Neill TW, Felsenberg D, Varlow J, Cooper C, Kanis JA, Silman AJ (1996) The prevalence of vertebral deformity in european men and women: the European Vertebral Osteoporosis Study. J Bone Miner Res 11:1010-1018

8. O'Neill TW, Cooper C, Algra D, Pols H, Agnusdei D, Dequeker J, Felsenberg D, Kanis J, Kruskemper G, Raspe H, Seelbach H, Silman A (1995) Design and development of a questionnaire for use in a multicentre study of vertebral osteoporosis in Europe: the European Vertebral Osteoporosis Study (EVOS). Rheumatol Eur $24: 75-81$

9. Cummings SR, Nevitt MC et al (1995) Risk factors for hip fracture in white women. N Engl J Med 332:767-773

10. Hernandez-Avila M, Romieu I, Parra S, Hernandez-Avila J, Madrigal H, Willett W (1998) Validity and reproducibility of a food frequency questionnaire to assess dietary intake of women living in Mexico City. Salud Publica Mex 40:133-140

11. (1994) Assessment of fracture risk and its application to screening for postmenopausal osteoporosis. Report of a WHO Study Group. World Health Organ Tech Rep Ser 843:1-129 
12. Black DM, Cummings SR, Stone K, Hudes E, Palermo L, Steiger P (1991) A new approach to defining normal vertebral dimensions. J Bone Miner Res 6:883-892

13. Kiel D (1995) Assessing vertebral fractures. National Osteoporosis Foundation Working Group on Vertebral Fractures. J Bone Miner Res 10:518-523

14. Ling X, Cummings SR, Mingwei Q, Xihe Z, Xioashu C, Nevitt M, Stone K (2000) Vertebral fractures in Beijing, China: the Beijing Osteoporosis Project. J Bone Miner Res 15:20192025

15. Black DM, Palermo L, Nevitt MC, Genant HK, Epstein R, San Valentin R, Cummings SR (1995) Comparison of methods for defining prevalent vertebral deformities: the Study of Osteoporotic Fractures. J Bone Miner Res 10:890-902

16. Eastell R, Cedel SL, Wahner HW, Riggs BL, Melton LJ 3rd (1991) Classification of vertebral fractures. J Bone Miner Res 6:207-215

17. Barros AJ, Hirakata VN (2003) Alternatives for logistic regression in cross-sectional studies: an empirical comparison of models that directly estimate the prevalence ratio. BMC Med Res Methodol 3:21

18. (2000) U.S. Census Bureau http://www.census.gov/main/www/ cen2000.html. In.

19. (2000) http://www.e-mexico.gob.mx/wb2/eMex/eMex_INEGI XII_Censo_general_de_poblacion_y_vivie. In.

20. Van der Klift M, De Laet CE, McCloskey EV, Hofman A, Pols HA (2002) The incidence of vertebral fractures in men and women: the Rotterdam Study. J Bone Miner Res 17:1051-1056

21. (2002) Incidence of vertebral fracture in europe: results from the European Prospective Osteoporosis Study (EPOS). J Bone Miner Res 17:716-724.

22. Cauley JA, Zmuda JM, Wisniewski SR, Krishnaswami S, Palermo L, Stone KL, Black DM, Nevitt MC (2004) Bone mineral density and prevalent vertebral fractures in men and women. Osteoporos Int 15:32-37

23. Tsai K, Twu S, Chieng P, Yang R, Lee T (1996) Prevalence of vertebral fractures in chinese men and women in urban Taiwanese communities. Calcif Tissue Int 59:249-253 